\title{
Kinematic variables of table vault on artistic gymnastics
}

CDD. 20.ed. 796.023

796.41

http://dx.doi.org/10.1590/1807-55092016000100097
Sarah Maria Boldrini FERNANDES

Paulo CARRARA* Júlio Cerca SERRÃO*

Alberto Carlos AMADIO*

Luis MOCHIZUKI**
*Escola de Educação Física e Esporte,

Universidade de São

Paulo, São Paulo, SP, Brasil.

**Escola de Artes Ciências e Humanidades, Universidade de São Paulo, São Paulo, SP, Brasil.

\begin{abstract}
The table vault is an event of male and female Artistics Gymnastics. Although it can be performed in a variety of rotations and body positions in different phases, it can be separated in three groups: handspring, Yurchenko and Tsukahara. It is believed that kinematic variables of vault may vary according to group of vault or gymnast body position, but few studies compares the real differences among the three groups of vaults, comparing and describing the variables in different phases. Vault kinematic variables could be diversifying according to the approach or position of the vaulting, but little has been studied about the biomechanical differences, comparing and describing behaviours at different stages. The aim of this study was to organize critical, objective and to systematize the most relevant kinematic variables to performance on vaulting. A Meta analysis over the basis Pubmed, Sport Discus and Web of Science were performed about this issue. From the selected references, we described and analyzed the kinematics of the table vault. Vault can be characterized in seven phases of analysis. Most of the studies are descriptive, and some do not descript all phases. Differences among vault variables according to group vaults, technical level and gender were analysed only in recent studies. There still gaps of knowledge about kinematic variables of table vault, in order to provide comprehensive information about all possibilities of vaults in this gymnastic event. It is concluded that kinematic variables of table vault depends upon vault group and may be considered to the improvement of technical performance. More researches are needed to approach the coaching interface with biomechanics applicable knowledge.
\end{abstract}

KEY WoRDS: Gymnastic; Vaulting; Kinematics.

\section{Introduction}

Vault is one of the artistic gymnastics events, either for males and females competitions. Since 2001, vault regulations include an approach running of $25 \mathrm{~m}$, a springboard and a rectangular table with a surface measuring $1.20 \mathrm{m \times x} 0.95 \mathrm{~m}$. The table height is different among males $(1.35 \mathrm{~m})^{1}$, females $(1.25 \mathrm{~m})^{2}$ and juniors categories $(1.15 \mathrm{~m})^{3}$. The competition regulations require from a gymnast to perform two vaults from five groups, characterized by different approaching positions on the table (FIGURE 1$)^{1}$.

For males, the number of vaults coded in each group are: 34 in group I (forward handspring), 24 in group II (handspring with $1 / 4$ turn in the first flight phase, Tsukahara), 19 in group III (round off entry, Yurchenko), 16 in group IV (round off entry with in group the first flight phase, Nemov) and 14 on group $\mathrm{V}$ (round off entry with turn in the first flight phase of the jump, Scherbo), in a total of 107 vaults $\operatorname{coded}^{1}$. For females, the number of vaults coded in each group are: 24 in group I (handspring), 14 in group II (handspring and salto), 12 in group III (1/4 or $1 / 2$ turn in the first flight phase, Tsukahara), 19 in group IV (round off entry and salto, Yurchenko) and 11 on group $V$ (round off entry with $1 / 2$ turn in the first flight phase), in total of 80 vaults coded ${ }^{2}$.

Due to those coded vaults, research would be needed about general concepts of vaulting biomechanics, to develop principles for qualitative application of biomechanics to improve movement performance and to reduce the risk of injury ${ }^{4}$. 
A) Handspring; B) Tsukahara; C) Yurchenko;

D) Nemov and;

E) Scherbo.
Therefore, one main need for research in gymnastics and biomechanics is to present objective and systematic knowledge about the apparatus and provide information to the coaches in field 5 .

An understanding of the biomechanics variables related to the vault groups, body position (tucked, piked or stretched), the number of rotations around the transversal and longitudinal body axis, gymnasts sectors and categories would provide information about the research gaps. Also, to present coaches with a comprehensive understand about what is already known ${ }^{6}$. If there are differences between vault groups would explain individual gymnast performance needing to attend

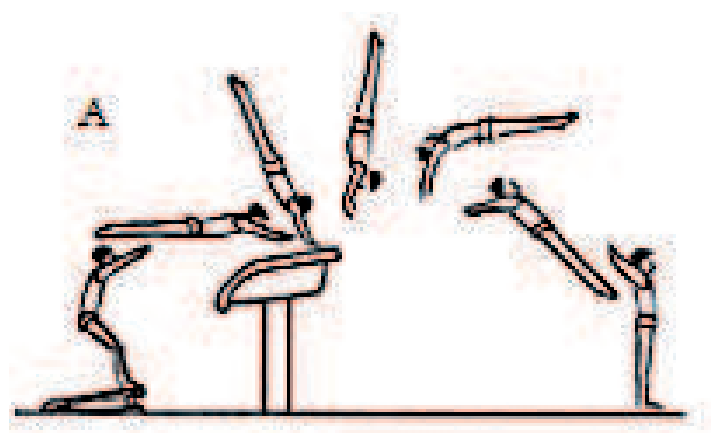

C

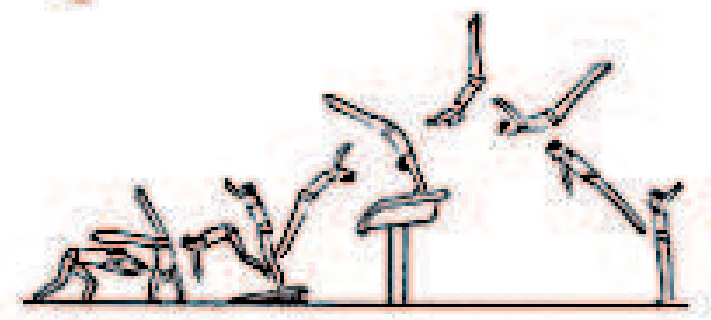

competition requirements. It is necessary to organize biomechanical-based classification for the exercises in artistic gymnastics ${ }^{7-11}$. In order to approach such proposal, is there biomechanics differences regarding the vault types and table height? Is there the group vault more preferable or efficient? The understanding of the performance variables in a sportive movement is fundamental to improve gymnasts technical achievements ${ }^{4}$. Such variables, when interpreted and manipulated, are important to understand the adaptations and limitations of movement patterns, by complete characterization of sportive movement, and to elaborate a plan of action to improve performance ${ }^{12}$.
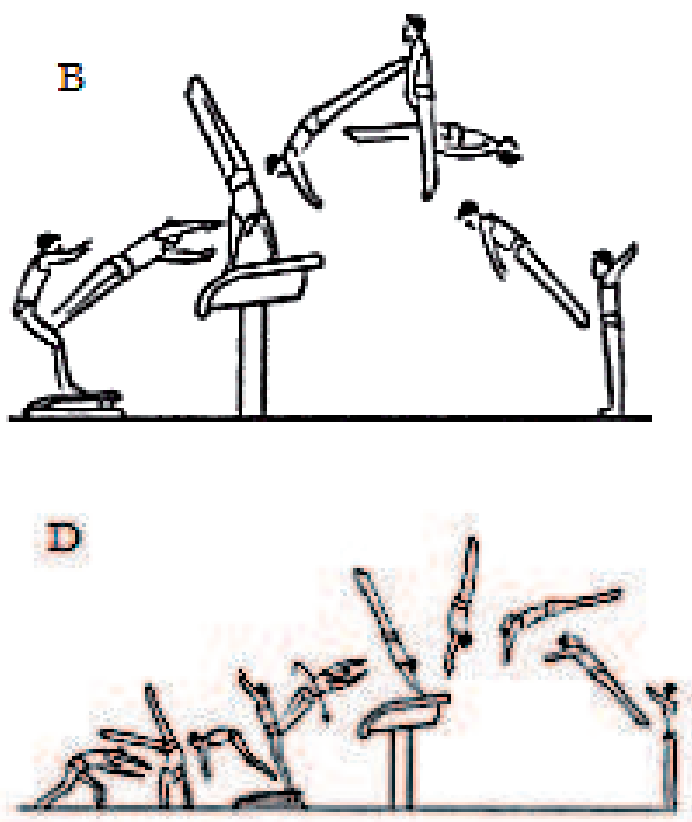

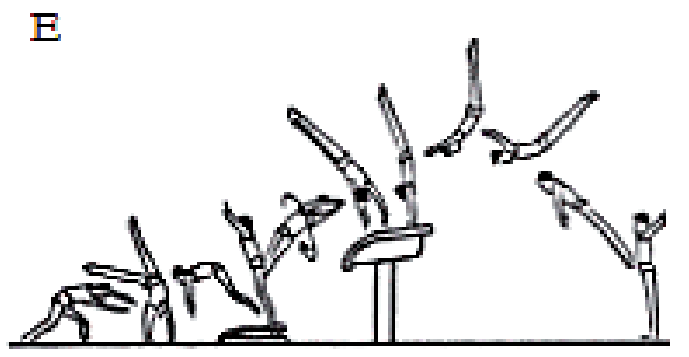

FIGURE 1 - Vault groups ${ }^{1}$.

The scientific questioning about the reference parameters that base coaches actions ${ }^{6}$. Due to the complexity and variability of motor actions in gymnastics, it is pertinent to analyze each event separately. Close monitoring of the evolution of skill on table vault apparatus is paramount for gymnastics coaching ${ }^{13}$.
Coaches' access to applied biomechanics knowledge is also limited because the youth of biomechanics means there are fewer narrative or meta-analysis review papers on sport biomechanics issues ${ }^{4}$. In Artistic sports where it is important the presentation, the technical level and the increase of complexity, it is necessary to analyse kinematic aspects of performance, and 
determine the variables which can lead to performance improvement or score increase ${ }^{6}$.

Besides being recognized as empiric by great part of scientific community, importance of such variables, most of the studies are descriptive, some are comparative among vault parameters to the final score ${ }^{5,14}$. There are few studies comparing the main variables in the vault event ${ }^{15-16}$, in special over different vault groups, in which the biomechanical factor is different ${ }^{17}$. It is believed that the kinematic variables of vault may vary according to the vault group, gender or technical level, but still lack of knowledge about the real differences among vault groups, mainly when considering direct methods of

\section{Method}

This meta-analysis research was conducted based in papers within the data basis: Pubmed, Sport Discus and Web of Science. This search was performed in those databases from 1980 up to 2015. Moreover, book of abstracts with reviewing process from International Society of Biomechanics, International Society of Biomechanics in Sports and Brazilian Society of Biomechanics were included. The keywords used in English were: "gymnastics" and "vault" and "kinematic"; and in Portuguese: "ginástica" and "salto" and "cinemática". From the resulting references, papers that have considered vault kinematics were selected for analysis in the present study. Biomechanics and kinematics are adequate to characterize the mechanics of causes and effects of movements and variables of performance ${ }^{12}$.

\section{Results and discussion}

\section{The gymnastics table}

The table vault is composed by a sequence of complex movements and is presented on male and female competitions ${ }^{1-2,20}$. As shown in measuring ${ }^{18-19}$. Sport coaches naturally want the best for their athletes to help them improve performance and reduce their risk of injury ${ }^{4,6}$.

After these considerations, the question arises from this scenario: what are the main parameters or vault phases that should be considered about gymnastics table vault? Are there essential variables which predict vault performance? Do the kinematic variables of vault vary over vault group, gender or technical level? The aim of this study is to present comprehensive information about the movement patterns of table vault, discuss the most relevant kinematic variables of vault performance and point out lacking points in research about this gymnastics event.

\section{Variables}

For an adequate understanding, the studies describing the characteristics and predictors of performance in vaults were grouped variables. The dependent variables were the vault group (group one to five) and body posture (tucked, picked or extended), as during vault 2 nd flight phase it is another factor of differentiating and increasing complexity and vault value. The independent variables were the gender (male or female), category (seniors, juniors or beginners) and technical level (Olympic, World Championship, international or national). Some studies refer to the former horse used for vault. They were included to allow observing the interdependence and relations among vault phases.

FIGURE 2, each vault can be divided into seven phases: 1) running; 2) jumping on springboard; 3) springboard support; 4) first flight phase; 5) table support; 6) second flight phase and 7) landing ${ }^{5,17,21-23}$. 
1: run;

2: jump on springboard;

3: springboard support

phase;

4: first flight phase:

5: support;

6: 2nd flight phase and;

7: landing.

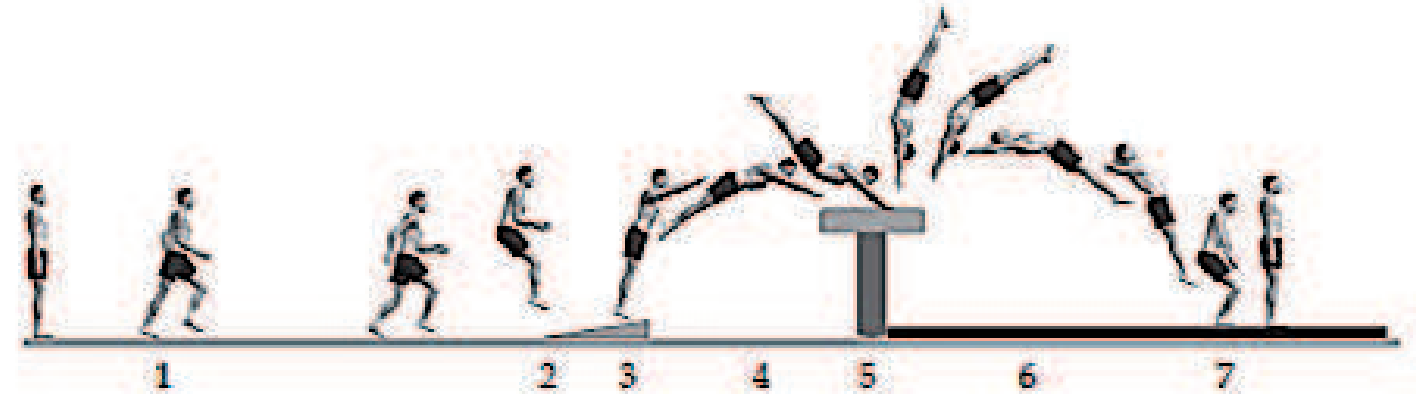

FIGURE 2 - Vault seven phases ${ }^{24}$.

The vaults may be categorized in: a) continuous rotation (were the movement rotations happen on the gymnast transversal plane) handspring and Yurchenko; and b) change of direction, which the movement rotation axis of the 2 nd flight is reverted in relation to the first flight ${ }^{25}$. Thus, the main first flight groups can be grouped in handspring, Tsukahara and Yurchenko ${ }^{5,26}$.

Within the 40 studies we have found, 18 studies (45\%) described handspring group, four studies (10\%) described Yurchenko group and two (5\%) described Tsukahara group. No studies were found about vaults from group VI or V. One reason for it could be because the entry for these groups are performed with $1 / 2$ turn or more in the 1 st flight phase, so they are more complex to be performed with similar vault values as the other groups. Besides, the number of codified vaults for group IV and V is only half of the number of codified group I, and two thirds of group II vaults, containing less options for a vault that best fit for a gymnast, considering the best vault values and penalties applicable.

Vault preparation occurs during running to springboard. The gymnast runs to increase the kinetic energy and increase the mechanical energy to the linear and angular rotations to be performed on the vault 2 nd flight ${ }^{16}$. Following, after the contact and leave the springboard, the 1st flight is the displacement with the feet from springboard to the hands contacting the table. After the 1st flight, the contact table phase begins with the preparation for the 2nd flight. On 2nd flight, the gymnast performs rotations and get ready for the vault final phase, which is the landing ${ }^{16,}$ 27. Vault lasts about two seconds of running, $0.1 \mathrm{~s}$ of springboard contact, $0.2 \mathrm{~s}$ of $1 \mathrm{st}$ flight and table contact, and one second of 2nd flight ${ }^{28}$.

The biomechanical characteristics that limits vaulting performance are related to the execution velocity, linear and angular body segments positions ${ }^{24}$ and the vault phases duration ${ }^{5,27}$ (described in FIGURE 1). The score attributed by a judge is highly related with the 1st flight duration, 2nd flight duration and height peak ${ }^{23,29}$; while for TAKEI $^{21}$ the centre of mass $(\mathrm{CM})$ horizontal displacement reach at 2nd flight peak would be the best predictor of judges' scores. To explain the relation between biomechanical parameters and vault values of different men's vault groups, Aticović ${ }^{24}$ applied a mathematical model to explain the final phase (2nd flight) of vault. Vaulting performance depends on: CM position and height in final phase; 1st flight mechanical parameters during table contact; base of table spring properties; segments acceleration and torques between gymnast and table ${ }^{30}$; strength, flexibility and acceleration ${ }^{31}$.

However, Schwiezer ${ }^{32}$ determined important mechanical variables for optimal vault performance: variation of hand placement, reaction forces at hand support phase, minimal distance between body CM and the edges of the table, minimal and maximum distances between body and the edge of the table while crossing the apparatus, position at which the gymnast hits the vaulting board, distance of the vaulting board, and landing distance behind the table.

Hetch vault (group 1 handspring - reverse rotation on 2 nd flight) was found in three (11\%) studies. It was a compulsory vault in Men's Artistic Gymnastics during the Olympic cycle 1993-1996. The Hecht vault required a low trajectory of $\mathrm{CM}$ during preflight, with a low vertical CM velocity and low angular velocity of the body at horse contact ${ }^{33}$. In contrast, the optimum handspring somersault required a high pre-flight trajectory, with a high angular velocity of the body and a high vertical velocity at horse contact ${ }^{33}$. This is useful for technical development considerations when learning from Hecht to handspring vaults.

Hetch vault is an unusual vault in gymnastics ${ }^{34-35}$. Unusual for elite competitions because it is not coded anymore ${ }^{1}$, but it is considered the first vault 
for beginners. Contact phase were studied and shoulder angles were emphasized to build models to understand the performance of Hetch vaul ${ }^{35}$. Studies about juniors or beginners categories were found, and the Hetch vault would be a good example of search for any kinematics variable differences from juniors to seniors, over an identical skill. Another paper advance on the relation between wrist and shoulder angles on junior female handspring vaults ${ }^{36}$. These comparisons would allow more knowledge about the common gymnast's errors and how to develop the vault technical progressions.

Optimization studies were applied to optimize performance scores for vaults with fixed rotation potential ${ }^{37-39}$. The increase in height of $0.4 \mathrm{~m}$ between real condition $(2.7 \mathrm{~m})$ and optimum simulation (3.1 $\mathrm{m})$ may seem rather high but is consistent with the heights reached in elite performances of handspring double front somersault (Roche) vaults $(3.0 \pm 0.1$ $\mathrm{m})$ which requires similar angular momentum ${ }^{29,39}$.

For Kasamatsu and Tsukahara vaults, horizontal $\mathrm{CM}$ velocity decreased, vertical CM velocity increased, and angular momentum was produced in the board contact phase. In addition, horizontal and vertical velocity decreased in the vault contact phase. However, no difference was observed between both vaults. The contribution of upper limbs to angular momentum about the centre of mass was higher for Kasamatsu vault than that for Tsukahara vault at vault takeoff ${ }^{40}$. The $\mathrm{CM}$ height contributes to vertical reception on landing, contributing with improved control. For high scores handsprings vaults, it was observed larger horizontal velocity and translational kinetic energy at takeoff from the board, larger vertical velocity and greater amplitude on 2nd flight and superior landing performance ${ }^{41}$.

For the Roche (handspring plus double salto tucked forward) vault comparisons, gymnasts with high score in competition had: 1) greater height of body CM and a more fully extended body position at the horse take-off; 2) greater height of body CM at the peak of post-flight, knee release, and touchdown on the mat; 3) greater horizontal and vertical displacements of body CM, greater somersaulting rotation, and longer time from the knee release to mat touchdown; and 4) markedly smaller landing point deductions ${ }^{29}$.

Modelling handspring was found with the former horse used for vault $\mathrm{t}^{42}$ and for the current table $\mathrm{e}^{39,43}$, while was not found for other vault groups. It was verified that changing the apparatus from horse to table has changed handspring vertical take-off velocity $^{13}$. But no studies were found regarding kinematics changes of other vaults.

ČUK et al. ${ }^{17}$ presented biomechanical characteristics of vault and the most important factors for a successful vault jump. These factors included morphologic characteristics, run velocity, length of flight on the springboard, duration of board contact, position of feet from springboard edge, duration of 1 st flight phase, duration of support on table phase, duration of 2 nd flight phase height of jump, distance from take-off 2nd flight phase, and landing.

Within the 40 studies found, only 13 (32\%) compared vault groups. The following vault phases are depicted for a deeper understanding of its importance regarding to different vault groups. The descriptions of principles can be used to improve the application of biomechanics in the qualitative analysis of sport technique ${ }^{4}$.

\section{Approach running}

The running approach is preliminary phase that allows gymnast to reach peak horizontal velocity at jumping, what will be relevant for the next phases ${ }^{44}$. It is when the gymnast accelerates towards the table until the last movement before springboard contact. Some studies about vault biomechanics ${ }^{25,} 29,45$ had shown that as higher velocity peak is; more favourable is the development of propulsion to reach enough height and distance for 2 nd flight rotations.

Furthermore, there are many studies reporting successful vault performances such as run speed, maximum speed on springboard, 1 st flight and 2nd flight position ${ }^{8,17,20,23,29,32,44}$.

For kinematics comparisons between the actual table and horse in vault, the running approach and springboard contact characteristics remained unchanged, as equipment modifications did not change gymnast performance in these initial phases ${ }^{13}$. An analysis of men's and women's vault showed that during ten years the running approach velocity have increased, except for Yurtchenko group vault ${ }^{44}$. For those authors, the technical improvement of gymnastics during these ten years led a rise of the vault values, what means increasing the number of rotations and the complexity of body positions, influencing on large velocity necessities ${ }^{44}$. Yurtchenko characteristics appear to be a factor limiting velocity, as round off entry requires more precise movements than jumping straightforward over the springboard.

Technical level of gymnast can determine the running approach acceleration to springboard. 
VELIČKOVIĆ et al. ${ }^{20}$ analyzed the running velocity of the last ten steps from the finalist gymnasts of the world championship (elite) and of the world cup (high level). In the last ten steps, gymnasts increase progressively velocity and reach the peak in the last step, being the elite $(9.95 \mathrm{~m} / \mathrm{s})$ faster than high level $(8.57 \mathrm{~m} / \mathrm{s})$ gymnasts. Therefore, elite gymnasts are more prepared to perform better vaults, due to larger final velocity and impulse, better adjustment and running precision ${ }^{20}$.

All vaults of Stuttgart World championship had the running approach analysed, and velocity patterns were depicted accordingly vault group and gender. Handspring vaults had shown larger mean velocities, followed by Tsukahara and Yurchenko group vaults. Men were faster than women (handspring: $8.3 \mathrm{~m} / \mathrm{s}$ versus $7.7 \mathrm{~m} / \mathrm{s}$; Tsukahara: $8.2 \mathrm{~m} / \mathrm{s}$ versus $7.5 \mathrm{~m} / \mathrm{s}$ ), except for Yurchenko vaults $(7.3 \mathrm{~m} / \mathrm{s}$ for both genders). These differences on running velocities may occur due to interaction of lower table height and lower vault value (number of rotations and body position) for women competition. The decreasing acceleration pattern during running was inversely proportional to velocity increase, aiming to target springboard. Considering the number of steps as a scale to estimate gymnast velocity ${ }^{20}$ or distance ${ }^{44}$ peak velocity occurs close to springboard, suggesting that larger velocity facilitates the subsequent execution of 1 st flight.

An increased necessity of running acceleration is related to vault score, and if there is an error during approaching, hardly it can be corrected ${ }^{26}$. Generally, gymnast builds up kinetic energy during a sprint and that energy is partitioned into linear and angular momentum during springboard phase. These moments dictate the linear and angular momentum carried into the vaulting table ${ }^{24}$.

\section{Springboard contact}

The jump on springboard starts when a gymnast jumps from the running track, after the last approaching step. Its objective is to transmit the impulse produced on running and on springboard to $1 \mathrm{~s}$ and 2 nd flight phases ${ }^{10}$. The energy provided from this approach will be redirected to the table by the springboard action ${ }^{27}$. At this instant it is important the gymnast posture, force generated by the gymnast, where this force is applied over the springboard, the velocity acquired and how the energy will be transferred ${ }^{15,27,46-47}$.

When gymnast's feet contact the springboard with foot, the ground reaction force peak is around ten times the body weight ${ }^{48}$. There is any factor related to the other phases that influence the springboard contact (vertical velocity, horizontal velocity and entrance angle), except the approach running ${ }^{46}, 49$. However, the springboard support phase can influence the subsequent phases ${ }^{15-16}$.

The position at which gymnasts hit the vaulting board is also important. Considering the handspring vault, jumping over the distal part of the springboard reduces more the gymnast horizontal velocity than jumping over the middle part ${ }^{32}$. In addition, the horizontal velocity of impacts was $18 \%$ higher over the distal part of the springboard, contributing more to the inversion of the gymnast due to larger horizontal velocity on anteroposterior direction ${ }^{27}$. This consideration is important as the developing categories of gymnasts who do not have enough power to springboard should precisely jump over the springboard distal part to achieve the handspring vault. Moreover, the handspring group is one of the most challenging vaults for gymnasts who are as tall as the table height, and are passive to fall over the table with their back. One rule adjustment in Brazil is to allow one springboard to be place over another for beginners' categories, lowering the difference between table and gymnast height and improving the propulsion ${ }^{3}$. Considering Tsukahara group, for example, the lateral hand position base is larger over the table, facilitating the small gymnast to pass over the table, besides allowing gymnasts to have visual contact during all vault phases, facilitating any skill corrections needed. Any of the found research relates table and gymnasts height to model the minimal kinematics parameters required to pass over the table, what would be useful for coaching purposes. Just one paper $^{31}$ associated training and kinematics variables in initial gymnasts categories (11-13 years old).

Another study analysing men's and women's vault kinematic parameters associated springboard contact and vault performance ${ }^{15}$. Women reached the springboard contact with lower entrance angle than men. By reducing $7 \%$ of horizontal or vertical velocity on springboard, it would reduce respectively by $13 \%$ and $25 \%$ of the distance on 2 nd flight ${ }^{15}$. Because 2nd flight distance is one parameter evaluated by judges ${ }^{1-2}$, the entrance velocity over the springboard can influence gymnast final score ${ }^{15}$. The distance of vaulting board ${ }^{32}$ and high take-off velocity was directly related to judge's score ${ }^{26}$.

\section{First flight phase}

The first flight phase starts at the first instant gymnast takes off the springboard until contact the 
table. Its aim is to displace body from springboard to the table, promoting velocity and optimum entrance angles for the 2 nd flight ${ }^{5,16,30}$. On the 1st flight phase, it is defined the vault group related to its rotation, by maintaining the same direction to contact the table (handspring and Yurtchenko) or by changing the direction (Tsukahara) ${ }^{18,30}$.

Dimitrova et al. ${ }^{11}$ monitored women hips kinematics in the main vault phases of different group vaults. The first flight mean acceleration was: for Tsukahara piked (group 2) $17.09 \mathrm{~m} / \mathrm{s}^{2}$, for Yurchenko stretched salto backward (group 3) $19.02 \mathrm{~m} / \mathrm{s}^{2}$ and for Handspring tucked salto forward (group 1) $21.83 \mathrm{~m} /$ $\mathrm{s}^{2}$, showing that for junior gymnasts, the vault group can influence the first flight acceleration ${ }^{11}$.

In Tsukahara vault group, there is a chance that gymnast touches the table with one hand before than another, this also might be a reason for the larger time of support ${ }^{19}$. This fact assists gymnast to complete a turn of up to $180^{\circ}$. The duration of 2 nd flight was larger for handspring, compared to Tsukahara group vault. However, the body position was not considered, what could influence in these results.

$\mathrm{KoH}$ and Jennings ${ }^{30}$ investigated the variations of body entrance angle on 1st flight (as consequence of segments angular position variation) or angular moment on 1 st flight (by segment angular velocity variation) would affect vault performance, understanding the posture of rotations and the 2 nd flight phase. It was analyzed the vaults performance of women's elite gymnasts, according to international judges observations and a model optimal vault was developed. This model had shown that when the angle body (entrance) is kept low during table contact, the angular momentum of 1 st flight increases, with incoming earns on support phase, producing efficient vaults. Therefore, the increase only in angular momentum to improve performance no 2nd flight may not happen due to the highly increase of velocity angular required. Similarly, higher body angles on contact were unattainable. A rise of CM on takeoff of table was essential to reach height and distance sufficient on 2nd flight. To compensate such factors, observed that, although as gymnasts lower angle body optimum, they increases partially CM rise and, mainly, velocity acquired, what provided larger height on 2nd flight.

Similarly, YeADON et al. ${ }^{47}$ analyzed elite gymnasts vault from Canadian national championships to establish how the characteristics of 1 st flight determine 2 nd flight performance. They found that peak height of CM on 2nd flight was correlated to $\mathrm{CM}$ vertical velocity on contact with the table; rotation velocity of body was correlated with shoulder angle on instant of support phase begin, and that the final result of vault, judges scores, were correlated with a height peak of CM during 2nd flight. Since 1st flight performance limits of 2 nd flight performance, the 1st flight must occur in an efficient manner. Thus, as larger the velocity is acquired a rise of CM during 1 st flight and entrance angle, as better the final performance of gymnast will be improved ${ }^{30,47}$.

Considering velocity, Yeadon et al. ${ }^{47}$ studied how 1 st flight vault influences 2 nd flight by means of vertical and horizontal velocity on vault Hetch and handspring vault. They have found that gymnasts that performed vault Hetch have shown horizontal velocity of $5.56 \mathrm{~m} / \mathrm{s}$ and vertical velocity of $3.38 \mathrm{~m} / \mathrm{s}$, while those performing vault handspring have shown horizontal velocity of $5.31 \mathrm{~m} / \mathrm{s}$ and vertical velocity of $3.76 \mathrm{~m} / \mathrm{s}$. During table contact, the gymnast interacts with the table to further refine post flight linear and angular momentum requirements, to achieve the vault's desired distance, height and rotation $s^{24}$. The simulations presented in handspring double salto ${ }^{43}$ demonstrated that changes in horizontal velocity and contact technique both have an influence on post-flight rotation potential. This find reinforces that increasing horizontal approach velocity would improve performance ${ }^{25}$.

SCHWIEZER ${ }^{32}$ determined mechanical variables important for optimal vault performance: variability of hand position, reaction force during the support phase of the hands, minimal distance between body $\mathrm{CM}$ and the far edge of the table while crossing the table, minimal and maximum distances between body and the far edge of the table while crossing the apparatus. The morphologic characteristics are important factors for a successful vault jump ${ }^{24}$. This is functional for beginners. It is usual to find gymnasts smaller than the vault table, without enough power to proper 2 nd flight over the table. Depending how far from the table's edge gymnasts place their hands, more susceptible they are to fall over the table, what characterize invalid vault (score will be zero), besides letting then to risk of injuries. The arms are in line with the torso at table touchdown and so the gymnast would need to modify his technique in order to achieve maximal rotation potential. Increasing both vertical velocity and angular momentum at table touchdown will improve performance ${ }^{43}$. 


\section{Second fligtht and landing}

The 2nd flight phase starts immediately after the end of support phase and ends before gymnast reaches the landing mats with his feet. This is when gymnast has to maintain a body posture, showing or not rotations on longitudinal and or on transversal axis. According to the gymnastics Code of Points ${ }^{1-2}$, judges must consider on 2 nd flight height and distance gymnast achieved from the table, as criteria for applying penalties. An excellent 2 nd flight depends on the characteristics of previous phases $20-21,23,29,46$. As faster is the last table approach, larger is the potential to generate impulse no vault. YEADON et al. ${ }^{39}$ found that increasing touchdown velocity and angular momentum lead to additional 2nd flight height and therefore to additional rotation potential.

The fast and intense impact on springboard and the push with upper limbs on support phase might increase height of 2nd flight, due to increase of kinetic energy. With larger height in 2nd flight, more time is available to complex rotations on transversal or longitudinal axis ${ }^{20}$, facilitating gymnast's control of subsequent phase.

The landing is determined when gymnast reaches the mat and finishes the vault. It is fundamental evaluation criteria for judges and influenced by performance of 1 st and 2 nd flights. While the 1 st flight depends of contact phase with springboard, the execution of landing depends on each of precedent phases and reflect the overall quality of vault ${ }^{29}$. In this phase, gymnast must reach the mat sticking on it, without more steps or jumps, and $\mathrm{CM}$ must be over the support base and any step, instability or oscillations of arm position may result in judges' deductions $s^{1-2,50}$.

All kinetic energy stored is lost on the landing mat and on gymnast body, and the impact magnitude depends about height of flight and complexity of movement ${ }^{51}$. For a safe landing, without more steps or fall, it is important that the gymnast reach the mat with a correct posture, increasing the chances to "stick" the landing (without moving) and allowing the adequate use of ground reaction force to hold rotation with lower muscular effort ${ }^{24,50-52}$.

For MARINSEC $^{51}$, knee angle defines if the landing is stable or not. If the gymnast show knee angles over $63^{\circ}$, means that the landing was wrong, and penalties are applied. Studies describing the main landing errors and variables that would influence that errors ${ }^{53}$ suggest soft landings are the most efficient, while rigid and deep landings may imply larger errors. Even when a gymnast lands softly, knees should not be bent to lower body momentum of inertia, because lowering momentum of inertia increases angular velocity, and the movement became faster, leading to additional steps during landing.

In brief, the approach running is influenced by the vault group, gender ${ }^{20}$ and technical level ${ }^{26,44}$. Distance of springboard to table was investigated by only one paper ${ }^{49}$ on handspring vault, focusing on how the distance can influence the approach running. Nonetheless, other kinematics variables were different in other vault phases for expert German gymnasts. Changing the springboard distance to table by only $0.10 \mathrm{~m}$ affected how far gymnasts' wrists were to back edge of the vaulting table and the take-off angle ${ }^{49}$. Further studies would help on improving other vault group performance, for beginner's categories and intermediate vault values as well, within an immediate possibility of changing vaulting parameters.

First flight duration was different according to the vault group ${ }^{11,47}$. No additional studies were found comparing gender or technical level differences. Although vertical velocity was similar in all phases, the mechanical needs are unequal, suggesting that the propulsion on vault is influenced by vault group, constraining the angular parameters as source of variation $^{19}$. Second flight duration were different according to the vault group ${ }^{19,30,40}$; and technical level ${ }^{21,29,54}$. No other studies were found comparing gender differences or relating vault and table height.

Body posture (tucked, picked or extended) during 2 nd flight phase, affects vault value and vault complexity, even though it was not the focus of evaluation of most studies found ${ }^{43}$. It is expected that by changing body posture would effect on kinematics. For example, the same vault in the code of points has more value added according to the body posture adopted on 2 nd flight ${ }^{1-2}$.

From five vault groups in the code of Points, we grouped them into three main vault groups: handspring, Tsukahara and Yurchenko. A kinematic variable depends upon the vault type. Handspring is a direct vault, without turns before de 2 nd flight. This means that less precision is needed to springboard for table contact, allowing larger velocity and height achieved on 2nd flight.

Tsukahara is characterized by a body round off rotation in 1 st flight, what mean loss of velocity compared to another group vaults. Hands placement makes the gymnast to spend more time over the table, lowering the 2 nd flight height. However, more vaults with higher score value are 
found in Tsukahara group than in Yurchenko group. Furthermore, Tsukahara vault group can be easier developed with beginners because the visual contact over the table.

Yurchenko is characterized by round off on springboard, what induces less velocity than handspring, but it uses more the springboard mechanical energy than Tsukahara, because is direct (no turns before 2nd flight). As handspring, simultaneous hand placement allows base to gymnast reach 2 nd flight higher than Tsukahara group vaults.
Most of studies are descriptive, and only the recent studies are comparing the differences of some high complexity vaults. Still to be researched the vault kinematic variables focusing differences among vault group, body posture on 2 nd flight, gender and technical level. There is a lack of information about performance within low and intermediary score vaults, for initial categories in both genders, in order to help gymnast development. In other gymnastics events, for example, studies regard about skill progressions ${ }^{55-56}$, a closer source of knowledge for coaching biomechanics interface ${ }^{6}$.

\section{Resumo}

Variáveis cinemáticas do salto sobre a mesa na ginástica artística

0 salto sobre a mesa é uma prova da ginástica artística, tanto no setor masculino quanto no setor feminino. Embora existam inúmeras combinações para a realização de um salto, podemos separá-los em três grupos: reversões, Yurchenko e Tsukahara. Acredita-se que as variáveis cinemáticas do salto podem variar de acordo com o tipo de abordagem ou posição corporal do ginasta, porem pouco se têm estudado acerca das reais diferenças entre os três grupos de saltos, comparando-os e descrevendo os comportamentos em diferentes fases. Assim, o objetivo deste estudo foi organizar de maneira crítica, objetiva e sistemática as variáveis cinemáticas mais relevantes para o performance no salto sobre a mesa. Foi realizada uma meta-análise nas bases de dados Pubmed, Sport Discus and Web of Science sobre 0 assunto. A partir das referências bibliográficas resultantes, foi descrita e analisada a cinemática do salto sobre a mesa. 0 salto foi caracterizado em sete fases de análise. A maior parte dos estudos é descritiva, e alguns não abordam todas as fases. As diferenças entre as variáveis dos saltos de acordo com os grupos de saltos, nível técnico e gênero foram analisadas somente em estudos mais recentes. Ainda há lacunas na pesquisa sobre as variáveis cinemáticas do salto sobre a mesa, para fornecer informação abrangente sobre as possibilidades de saltos neste aparelho da ginástica artística. Concluiu-se que as variáveis cinemáticas do salto sobre a mesa dependem do tipo de salto e devem ser consideradas para a melhora da performance técnica. Mais pesquisas são necessárias para que uma interface entre 0 conhecimento da biomecânica e a aplicação prática seja abrangente ao técnico de ginástica.

PalavRAs-chave: Biomecânica; Performance; Técnicos.

\section{References}

1. Fédération Internationale de Gymnastique. 2013-2016 Code of points: men's artistic gymnastics. Lausanne: FIG; 2015.

2. Fédération Internationale de Gymnastique. 2013-2016 Code of points: women's artistic gymnastics. Lausanne: FIG; 2015.

3. Confederação Brasileira de Ginástica. Regulamento técnico 2015: ginástica artística masculina - programa competitivo. Aracaju: CBG; 2015.

4. Knudson D. Qualitative biomechanical principles for application in coaching. Sports Biomech. 2007;6:109-18.

5. Prassas S, Kwon Y-H, Sands WA. Biomechanical research in artistic gymnastics: a review. Sports Biomech. 2006;5:261-91.

6. Irwin G, Bezodis IN, Kerwin DG. Biomechanics for coaches. In: Jones R, Kingston K, editors. An introduction to sports coaching: connecting theory to practice. London: Routledge; 2013. p.145-60. 
Fernandes SMB, et al.

7. Knoll K, editor. Basic biomechanical relationships at pushoff for handspring forward vaults. Proceedings of XX International Symposium on Biomechanics in Sports; 2002; Extremadura, SPA. Extremadura: University of Extremadura; 2002.

8. Krug J, Knoll K, Koethe T, et al. Running approach velocity end energy transformation in difficult vaults in gymnastics. Proceedings of XVI International Symposium on Biomechanics in Sports; 1998; Konstanz, GER. Konstanz: Universitatsverlang Konstanz; 1998.

9. Penitente G, Merni F, Fantozzi S, et al. Kinematics of the springboard phase in Yurchenko-style vaults. Proceedings of XXV International Symposium on Biomechanics in Sports; 2007; Ouro Preto, BR. Outro Preto: Universidade Federal de Minas Gerais; 2007.

10. Sano S, Ikegami Y, Nunome H, et al. The continuous measurement of the springboard reaction force in gymnastic vaulting. J Sports Sci. 2007;254:381-91.

11. Dimitrova B, Tankusheva N, Petrova M. Velocity gradient-basic methodological classification of vault. Res Kines. 2015;43:66-70.

12. Amadio AC, Serrão JC. Contextualização da biomecânica para a investigação do movimento: fundamentos, métodos e aplicaçôes para análise da técnica esportiva. Rev Bras Educ Fís Esporte. 2007;21:61-85.

13. Irwin G, Kerwin DG. The influence of the vaulting table on the handspring front somersault. Sports Biomech. 2009;82:114-28.

14. Farana R, Uchytil J, Zahradník D, et al. The "Akopian" vault performed by elite male gymnasts: which biomechanical variables are related to a judge's score? Acta Gymnica. 2015;45:33-40.

15. Bento MF, Yamauchi MS, Carrara P, et al. Análise biomecânica do salto sobre a mesa: relaçáo entre o tipo de salto e seus parâmetros cinemáticos. XII Congresso Brasileiro de Biomecânica; 2007; Águas de São Pedro, BR. Rio Claro: UNESP; 2007.

16. Mochizuki L, Tupiniquim C, Serrão JC, et al. Análise biomecânica do salto sobre a mesa: relação entre parâmetros cinemáticos e tempo de voo. XI Congresso Brasileiro de Biomecânica; 2005; João Pessoa, BR. João Pessoa: Sociedade Brasileira de Biomecânica; 2005.

17. Čuk I, Karacsony I. Vault: methods, ideas, curiosities, history. Ljubljana: ŠTD Sangvinčki; 2004.

18. Bradshaw E, Hume P, Calton M, et al. Reliability and variability of day-to-day vault training measures in artistic gymnastics. Sports Biomech. 2010;9:79-97.

19. Farana R, Uchytil R, Jandacka D, et al. Comparison of the key kinematic parameters of difficult handspring and tsukahara vaults performed by elite male gymnasts. 30th Conference of Biomechanics in Sports; 2012; Melbourne, AUS. Melbourne: ISBS; 2012.

20. Veličković S, Petković D, Petković E. A case study about differences in characteristics of the run-up approach on the vault between top class and middle class gymnasts. Sci Gym. 2011;3:25-34.

21. Takei Y, Dunn JH, Blucker EP. Somersaulting techniques used in high-scoring and low-scoring Roche vaults performed by male olympic gymnasts. J Sport Sci. 2007;25:673-85.

22. Ferkolj M. A kinematic analysis of the handspring double vault forward tucked on a new style of vaulting table. Sci Gym. 2010;2:35-47.

23. Aticović. A, Smaljović. N. Relation between vault dificult values and biomechanical parameters in men's artistic gymnastic. Sci Gym. 2011;3:91-105.

24. Atiković A. New regression models to evaluate the relationship between biomechanics of gymnastic vault and initial vault difficulty values. J Hum Kinet. 2012;35:119-26.

25. Takei Y. Techniques used in performing handspring and salto forward tucked in gymnastic vaulting. Int J Sports Biom. 1988;4:260-81.

26. Bradshaw E. Gymnastics. Sports Biomech. 2004;3:125-44.

27. Coventry E, Sands WA, Smith SL. Hitting the vault board: implications for vaulting take-off - a preliminary investigation. Sports Biomech. 2006;5:63-75.

28. Dillman CJ, Cheetham PJ, Smith S. A kinematic analysis of men's olympic long horse vaulting. J Appl Biomech. 1985;1:96-110.

29. Takei Y. The roche vault performed by elite gymnasts: somersaulting technique, deterministic model, and judges' scores. J Appl Biomech. 2007;23:1-11.

30. Koh M, Jennings L. Strategies in preflight for an optimal Yurchenko layout vault. J Biomech. 2007;40:1256-61.

31. Kochanowicz A, Kochanowicz K, Sawczyn S. Special fitness and the effectiveness of technical preparation in gymnastic vault event in athletes at the directed stage. Balt J Health Phys Activ. 2009;1:70-8. 
32. Schwiezer L. Vaults with the new table. Lausanne: International Gymnastics Federation; 2003.

33. King MA, Yeadon MR, Kerwin DG. A two-segment simulation model of long horse vaulting. J Sport Sci. 1999;17:313-24.

34. Takei Y, Blucker EP, Nohara H, et al. The Hecht vault performed at the 1995 World Gymnastics Championships: Deterministic model and judges' scores. J Sports Sci. 2000;18:849-63.

35. King MA, Yeadon MR. Factors influencing performance in the Hecht vault and implications for modelling. J Biomech. 2005;38:145-51.

36. Penitente G, Sands WA. Exploratory investigation of impact loads during the forward handspring vault. J Hum Kinet. 2015;46:59-68.

37. Gervais P. A prediction of an optimal performance of the handspring $11 / 2$ front salto longhorse vault. J Biomech. 1994;27:67-75.

38. Koh M, Jennings L, Elliott B, et al. A predicted optimal performance of the Yurchenko layout vault in women's artistic gymnastics. J Appl Biomech. 2003;19:187-204.

39. Yeadon MR, Jackson MI, Hiley MJ. The influence of touchdown conditions and contact phase technique on post-flight height in the straight handspring somersault vault. J Biomech. 2014;47:3143-8.

40. Motoshima Y, Maeda A. Kasamatsu versus Tsukahara vault. Sci Gym J. 2015;7:15-24.

41. Takei Y, Blucker EP, Dunn JH, et al. A three-dimensional analysis of the men's compulsory vault performed at the 1992 Olympic Games. J Appl Biomech. 1996;12:237-57.

42. Dainis A. A model for gymnastics vaulting. Med Sci Sports Exerc. 1981;13:34-43.

43. Hiley MJ, Jackson MI, Yeadon MR. Optimal technique for maximal forward rotating vaults in men's gymnastics. Hum Mov Sci. 2015;42:117-31.

44. Naundorf F, Brehmer S, Knoll K, et al. Development of the velocity for vault runs in artistic gymnastic for the last decade. 26th Conference of Biomechanics in Sports; 2008; Seoul, KOR. Seoul: ISBS; 2008.

45. Takei Y. Three-dimensional analysis of handspring with full turn vault: deterministic model, coaches' beliefs, and judges' scores. J Appl Biomech. 1998;14:190-210.

46. Heinen T, Vinken PM, Jeraj D, et al. Movement regulation of handsprings on vault. Res Q Exerc Sport. 2013;84:68-78.

47. Yeadon MR, King MA, Sprigings EJ. Pre-flight characteristics of Hecht vaults. J Sport Sci. 1998;16:349-56.

48. Greenwood M, Newton JW. Direct force meansurements of the vault take-off in gymnastics. XIV International Symposium on Biomechanics in Sport; 1996; Lisboa, POR. Lisboa: Universidade Técnica de Lisboa; 1996.

49. Heinen T, Jeraj D, Thoeren M, et al. Target-directed running in gymnastics: the role of the springboard position as an informational source to regulate handsprings on vault. Biol Sport. 2011;28:215-21.

50. Mills C, Yeadon MR, Pain MTG. Modifying landing mat material properties may decrease peak contact forces but increase forefoot forces in gymnastics landings. Sports Biomech. 2010;9:153-64.

51. Marinšec M. Basic landing characteristics and their application in artistic gymnastic. Sci Gym. 2010;2:59-67.

52. Mills C, Pain MT, Yeadon MR. Modeling a viscoelastic gymnastics landing mat during impact. J Appl Biomech. 2006;22:103-11.

53. Marinšec M. Landing characteristics in the men's floor exercise on European Championships 2004. Sci Gym. 2009; 1:31-9.

54. Takei Y, Dunn HJ, Blucker EP. Techniques used in a high-scoring and low-scoring 'Roche' vaults performed by elite male. Sports Biomech. 2003;2:141-62.

55. Irwin G, Kerwin D. Biomechanical similarities of progressions for the longswing on high bar. Sports Biomech. 2005; 4:163-78.

56. Irwin G, Kerwin DG. Inter-segmental coordination in progressions for the longswing on high bar. Sports Biomech. 2007;6:131-44.

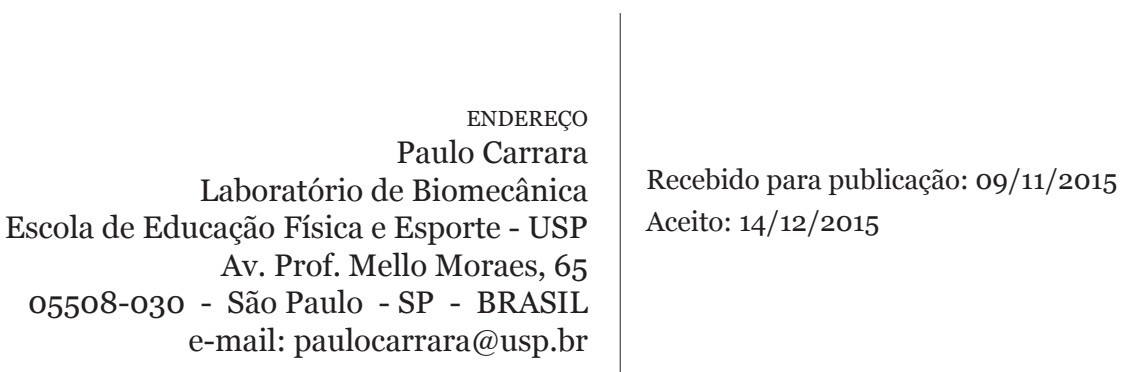

